\title{
The molecular basis of procalcitonin synthesis in different infectious and non-infectious acute conditions
}

\author{
Volume 3 Issue 2 - 2016 \\ Zsolt Becze,' Zsolt Moln r, J nos Fazakas \\ 'Department of ENT, Siofok District Hospital, Hungary \\ 2Department of Anesthesiology and Intensive Therapy, Faculty of \\ Medicine, University of Szeged, Hungary \\ ${ }^{3}$ Department of Transplantation and Surgery, Faculty of \\ Medicine, Semmelweis University, Hungary
}

Correspondence: Zsolt Becze, Department of ENT, Siofok District Hospital, Semmelweis University, Siofok, Hungary; Email zsbecze@t-oline.hu

Received: March 01, 2016 | Published: March 14, 2016

\begin{abstract}
Abbreviations: PCT, Procalcitonin; PAMP, Pathogen Associated Molecular Pattern; IL-1 $\beta$, Interleukin-1 Beta; IFN- $\Gamma$, Interferon Gamma; LRTI, Lower Respiratory Tract Infection; IL-17, Interleukin-17; CPR, Cardiopulmonary Resuscitation; IRI, IschemiaReperfusion Injury; DAMP, Damage Associated Molecular Pattern; ICU, Intensive Care Unit
\end{abstract}

\section{Introduction}

Procalcitonin (PCT) has been considered as a suitable tool for early detection differential diagnosis of bacterial infections and also for tailoring antibiotic therapy better ${ }^{1}$. However, there are several other factors influencing PCT production apart from bacterial infections only. Understanding the molecular basis of PCT synthesis, which is determined by the interaction between the initiating insult (infections or non-infectious injuries) and the host response summarized in the current review, will help us to the interpret PCT levels at the bedside with a greater confidence ${ }^{2-4}$.

\section{PCT synthesis in infections}

Bacterial infections: By and large PCT levels are elevated in bacterial infections as reported by several studies, but the feature of the response can be different. For example higher peak PCT concentrations are expected in Gram negative as compared to Gram positive infections Furthermore, differences may also be seen even within the family of Gram negative bacteria: as higher peak PCT concentrations can be detected in Enterobacteriaceae, as compared to non-fermentative Gram negatives or obligate Gram negative anaerobes. ${ }^{5,6}$ This is due to the polymorphism of the pathogen associated molecular patterns (PAMP) resulting in slightly different cytokine profiles hence different PCT values. In neutropenic patients, as the vast majority of the PCT synthesis is originated from the monocytes and macrophage cells, an attenuated response is expected with lower PCT levels ${ }^{7-11}$.

Viral infections: Linscheid and coworkers has shown in differentiated adipocyte cell culture that addition of interleukin-1 beta (IL-1 $\beta$ ) has induced the synthesis of PCT while the addition of IL-1 $\beta$ and interferon-gamma (IFN- $\gamma$ ) concomitantly has blocked it ${ }^{12,13}$. In viral infections the host $\mathrm{T}$ helper lymphocytes are forced to produce IFN- $\gamma$ which has a negative feed-back effect on the synthesis of (IL$1 \beta$ ), which is the main trigger of PCT induction. However, peak PCT concentrations would very seldom reach that of seen in bacterial infections. This is also true for chronic viral infections as can be seen in HIV infections, the peak concentration and the cut-off are considered to be lower ${ }^{14,15}$. The discriminative effect of the PCT can be used in the clinical practice as described in the French and German guidelines for the management of meningitis ${ }^{16,17}$ and in the antibiotic reduction in case of lower respiratory tract infections (LRTI) ${ }^{18}$, (Figure 1). Nevertheless, it is also important to acknowledge that bacterial super-, or co-infections can facilitate the synthesis of PCT, which makes the interpretation of PCT results more difficult under such circumstances, therefore, detailed clinical and microbiological assessment of the patient is inevitable to make appropriate decisions.

Fungal infections: Initially it was considered in a paper by Huber that PCT has no value in invasive fungal infections ${ }^{19,20}$. This was based on the finding that the magnitude of PCT elevation was far less than expected. However, more recent results reported that there may be a detectable PCT response in certain cases of invasive fungal infections, although there are substantial differences in the PCT levels found $5,21,22$. This could be due to the different host response to different Candida species, which should be tested by further studies ${ }^{23}$. One of the reasons why PCT concentrations are lower in fungal infections than in bacterial infections is the increased synthesis of IFN- $\gamma$ and IL-17 as part of the intact immune response for fungal infections, both of which are able to decrease/block the induction of PCT synthesis ${ }^{24}$. In cases of mixed bacterial-fungal infections, often seen in intensive care patients, we face similar diagnostic difficulties as discussed in the previous paragraph. As the blocking effects of IFN- $\gamma$ and interleukin-17 (IL-17) on PCT production can be overwhelmed by host's response for bacterial super-infection, PCT synthesis can be detected but the magnitude may be lower than seen in bacterial infection only. To overcome this diagnostic challenge the complex 
evaluation of PCT levels with fungal infection markers such as $\beta$-Dglucan, galacto-mannan and combining it with the Candida score is recommended ${ }^{25}$.

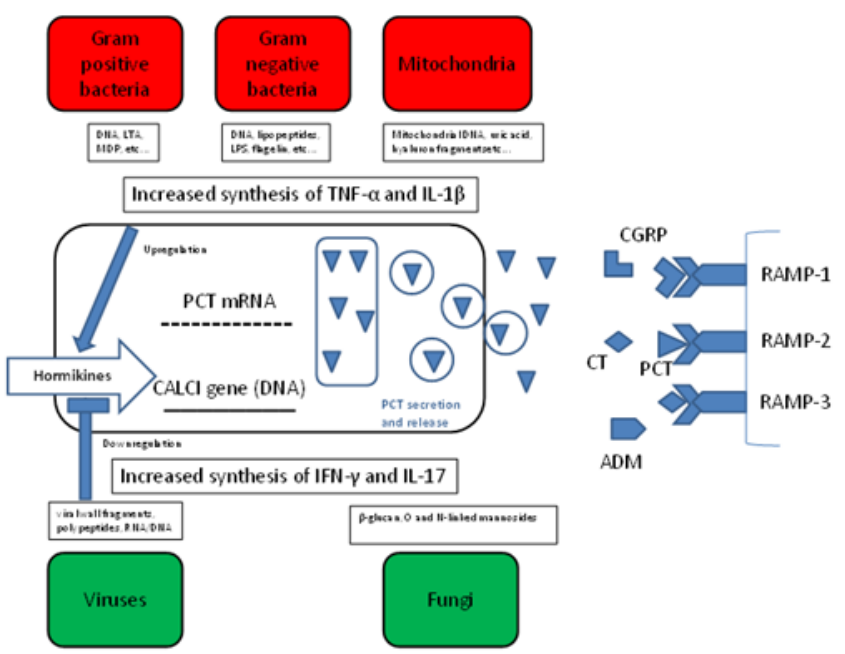

Figure I Schematic pictures of PCT induction in different infectious and noninfectious conditions and the receptorial interaction between the CALC gene family proteins.

DNA: Desoxy-Ribonucleic Acid; LTA: Leukotrien A; MDP: Metal-Dependent Phosphohydrolase; LPS: Lipopolysacharide; TNF-A: Tumor Necrosis Factor Alpha; IL- I $\beta$ : Interleukin- I Beta; PCT: Procalcitonin; CALCI Gene: Calcitonin I Gene; IFN- : Interferon Gamma; IL- I7: Interleukin- I7; RNA: Ribonucleic Acid; CGRP: Calcitonin Gene Related Protein;CT:Calcitonin;ADM:Adrenomedullin; RAMP-I, 2, 3: Receptor Activity-Modifying Protein I, 2, 3.

\section{Non-infective causes of PCT elevation}

Unspecific PCT elevations can also be found in the absence of infection ${ }^{26,27}$. In medical patients, non-specific PCT elevations can be seen due to several reasons. For example in some malignancies like the small cell lung carcinoma, bronchial carcinoma, the C-cell carcinoma of the thyroid gland and neuroendocrine tumors of the gastrointestinal system PCT can be elevated ${ }^{28,29}$. Medications, like anti-thymocyte-globulins used in transplantation medicine also can induce a cytokine storm with the consequence of PCT mono-induction ${ }^{30}$. In cardiogenic shock ${ }^{31}$, cardio-pulmonary resuscitation (CPR) ${ }^{32}$, sterile pancreatitis ${ }^{33}$ and rhabdomyolysis due to the ischemiareperfusion injury (IRI) induced damage associated molecular pattern (DAMP) substantial PCT increase can be detected ${ }^{34}$. After surgery a DAMP initiated PCT mono-induction are very often present, with its peak on the first or second post-operative days followed by a gradual decrease thereafter. ${ }^{35}$

In surgical patients with early infectious complications, DAMP and PAMP take place in a parallel fashion resulting in a synergistic effect on the inflammatory response and a re-induction of PCT production will take place resulting in an increasing or "not-decreasing" tendency of the daily PCT levels. If infectious complications occur at a later stage of the patients' ICU stay, PCT will increase again but the absolute values may be lower as if it had happened during the early stage, although the clinical significance (i.e.: the severity of the infection) may be just as severe. Although medical and surgical patients are different as far as the inflammatory response, hence the PCT absolute values are concerned, but changes in the kinetics of PCT, i.e., interception of decreasing kinetics or in fact a sudden increase may carry invaluable information and helps the clinician to change course of treatment early. ${ }^{36}$

\section{Conclusion}

Procalcitonin is very useful marker in the critically ill, but single cut-off values are very difficult to define as it is affected by several confounding factors. However, the dynamics of PCT values may provide a more relevant information about the onset of bacterial infections and potentially could be used in assisting antimicrobial therapy. In viral and fungal infections evaluation is more difficult, but with careful assessment of the patients' medical history, current complaints, results of the diagnostic tests and combining these with PCT values may have some merit, which may also serve as a very interesting research topic for the future.

\section{Acknowledgments}

None.

\section{Conflicts of interest}

None.

\section{References}

1. Schuetz P, Mueller B Procalcitonin: an effective screening tool and safe therapeutic decisionmaking aid for emergency department patients with suspected sepsis. Annals of Emergency Medicine. 2015;66(3):318-319.

2. Becze Z, Zsolt M, János F Can procalcitonin levels indicate the need for adjunctive therapies in sepsis? International Journal of Antimicrobial Agents. 2015;46(1):S13-S18.

3. Trasy D, Nemeth M, Osztroluczki A et al. Early procalcitonin kinetics may indicate effective empirical antibiotic therapy within hours after starting treatment (a pilot study). Intensive Care Med. 2013;39(Suppl 2):P0233.

4. Singer M, Deutschman CS, Seymour CW et al. The Third International Consensus Definitions for Sepsis and Septic Shock (Sepsis-3). JAMA. 2016;315(8):801-810.

5. Brodská H, Malíčková K, Adámková V et al. Significantly higher procalcitonin levels could differentiate Gramnegative sepsis from Gram-positive and fungal sepsis. Clin Exp Med. 2013;13(3):165-170.

6. Christian L, Marta F, Amedeo M et al. Procalcitonin Levels in GramPositive, Gram-Negative, and Fungal Bloodstream Infections. Disease Markers. 2015;2015(2015):8

7. Linscheid P, Seboek D, Schaer DJ et al. Expression and secretion of procalcitonin and calcitonin gene-related peptide by adherent monocytes and by macrophage-activated adipocytes. Crit Care Med. 2004;32(8):1715-1721.

8. Becker KL, Snider R, Nylen ES Procalcitonin in sepsis and systemic inflammation: a harmful biomarker and a therapeutic target. British Journal of Pharmacology. 2010;159(2):253-264.

9. Anna CR, Alexander K, Susan F et al. Procalcitonin Improves the Glasgow Prognostic Score for Outcome Prediction in Emergency Patients with Cancer: A Cohort Study. Disease Markers. 2015;2015(2015):9.

10. Hangai S, Nannya Y, Kurokawa M Role of procalcitonin and Creactive protein for the discrimination between tumor fever and infection in patients with hematological diseases. Leuk Lymphoma. 2015;56(4):910-914.

11. Matti V, Koivulaa I, Jantunena E, et al. IL-10 combined with procalcitonin improves early prediction of complications of febrile neutropenia in hematological patients. Cytokine. 2012;60(3):787-792.

12. Christ-Crain M, Muller B Procalcitonin on the dusty way to the Holy Grail: a progress report. Yearbook of Intensive Care and Emergency Medicine. 2005;2015:461-476. 
13. Linscheid P, Seboek D, Nylen ES, et al. In Vitro and in Vivo Calcitonin I Gene Expression in Parenchymal Cells: A Novel Product of Human Adipose Tissue. Endocrinology. 2003;144(12):5578-5584.

14. Schleicher GK, Herbert V, Brink A, et al. Procalcitonin and C-reactive protein levels in HIV-positive subjects with tuberculosis and pneumonia. Eur Respir J. 2005;25(4):688-692.

15. Jeena $P$ The role of HIV infection in acute respiratory infections among children in sub-Saharan Africa. Int J Tuberc Lung Dis 2005;9(7):708-715.

16. Raffi F, Xavier D Practice guidelines for acute bacterial meningitidis (except newborn and nosocomial meningitis). 17th Consensus Conference on Anti-infective Chemotherapy (SPILF). 2008

17. Meyding-Lamadé U Virale Meningoenzephalitis; Leitlinien für Diagnostik und Therapie in der Neurologie; Herausgegeben von der Kommission "Leitlinien" der Deutschen Gesellschaft für Neurologie. Thieme Verlag, Stuttgart, Germany. 2012

18. Christ-Crain M, Opal SM Clinical review: The role of biomarkers in the diagnosis and management of communityacquired pneumonia. Crit Care. 2010;14(1):203.

19. Huber W, Schweigart U, Bottermann P Failure of PCT to Indicate Severe Fungal Infection in Two Immunodeficient Patients. Infection. 1997;25(6):377-378.

20. Eloy Interet du dosage de la procalcitonine dans les infections profondes fongiques a Candida. Ann Biol Clin. 2001;59:502-505.

21. Wacker C, Prkno A, Brunkhorst FM, Schlattmann P Procalcitonin as a diagnostic marker for sepsis: a systematic review and meta-analysis. Lancet Infect Dis. 2013;13(5):426-435.

22. Charles PE, Dalle F, Aho S, et al. Serum procalcitonin measurement contribution to the early diagnosis of candidemia in critically ill patients. Intensive Care Med. 2006;32:1577-1583.

23. Bishop BM, Bon JJ, Trienski TL, et al. Effect of Introducing Procalcitonin on Antimicrobial Therapy Duration in Patients With Sepsis and/or Pneumonia in the Intensive Care Unit. Ann Pharmacother. 2014;48(5):577-583.

24. Delsing CE, Gresnigt MS, Leentjens J, et al. Interferon-gamma as adjunctive immunotherapy for invasive fungal infections: a case series. BMC Infectious Diseases. 2014;14:166.
25. Knitsch W, Vincent JL, Utzolino S, et al. A Randomized, Placebocontrolled Trial of Preemptive Antifungal Therapy for the Prevention of Invasive Candidiasis Following Gastrointestinal Surgery for Intraabdominal Infections. Clin Infect Dis 61. 2015; (11):1671-1678.

26. Uzzan B, Cohen R, Nicolas P, Procalcitonin as a diagnostic test for sepsis in critically ill adults and after surgery or trauma: a systematic review and meta-analysis. Crit Care Med. 2006;34(7):1996-2003.

27. Meisner M, Tschaikowsky K, Hutzler A, et al. Postoperative plasma concentrations of procalcitonin after different types of surgery. Intensive Care Med. 1998;24(7):680-684.

28. Jürgen K, Anne P, Friedhelm R, et al. Basal and Stimulated Calcitonin and Procalcitonin by Various Assays in Patients With and Without Medullary Thyroid Cancer. Clinical Chemistry. 2011;57(3): 467-474.

29. Kaczka K, Mikosiński S, Fendler W, et al. Can procalcitonin be useful for medullary thyroid cancer? Endokrynol Pol. 2010;61(5):430-436.

30. Ogasawara $\mathrm{T}$, Umezawa $\mathrm{H}$, Kato $\mathrm{S}$, et al. Intrathoracic Administration of OK-432 Elevates the Serum Procalcitonin Levels. Intern Med. 2012;51(19):2727-2731

31. de Werra I, Jaccard C, Corradin SB, et al. Cytokines, nitrite/nitrate, soluble tumor necrosis factor receptors, and procalcitonin concentrations: Comparisons in patients with septic shock, cardiogenic shock, and bacterial pneumonia. Crit Care Med. 1997 1997;25(4):607-613.

32. Hottenrott S, Schummer W Value of procalcitonin as an outcomeParameter after cardiacarrest; Resuscitation. 2013;84(1):e25-e26.

33. Oláh A, Belágyi T, Issekutz A, Value of procalcitonin quick test in the differentiation between sterile and infected forms of acute pancreatitis. Hepato-Gastroenterology. 2005;52(61):243-245.

34. Annborn M, Dankiewicz J, Erlinge D, et al. Procalcitonin after cardiac arrest: An indicator of severity of illness, ischemia-reperfusion injury and outcome. Resuscitation. 2013;84(6):782-787.

35. Amin DN, Pruitt JC, Schuetz P Influence of major cardiopulmonary surgery on serum levels of procalcitonin and other inflammatory markers. Anaesth Intensive Care. 2012;40(5):760-766.

36. Clec'h C, Fosse JP, Karoubi P, et al. Differential diagnostic value of procalcitonin in surgical and medical patients with septic shock. Crit Care Med. 2006;34(1):102-107. 